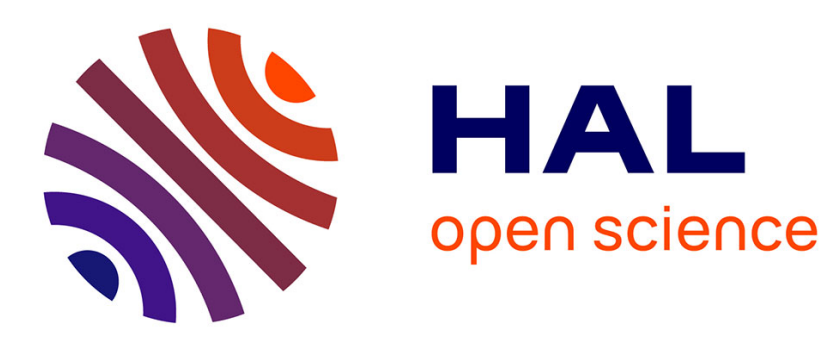

\title{
Fuzzy semi-quantitative approach for probability evaluation using Bow-Tie analysis
}

Houssein Abdo, Jean-Marie Flaus, François Masse

\section{To cite this version:}

Houssein Abdo, Jean-Marie Flaus, François Masse. Fuzzy semi-quantitative approach for probability evaluation using Bow-Tie analysis. 27th European Safety and Reliability annual conference (ESREL 2017), Jun 2017, Portoroz, Slovenia. pp.2597-2605. ineris-01853453

HAL Id: ineris-01853453

https://hal-ineris.archives-ouvertes.fr/ineris-01853453

Submitted on 7 Sep 2018

HAL is a multi-disciplinary open access archive for the deposit and dissemination of scientific research documents, whether they are published or not. The documents may come from teaching and research institutions in France or abroad, or from public or private research centers.
L'archive ouverte pluridisciplinaire HAL, est destinée au dépôt et à la diffusion de documents scientifiques de niveau recherche, publiés ou non, émanant des établissements d'enseignement et de recherche français ou étrangers, des laboratoires publics ou privés. 


\title{
Fuzzy semi-quantitative approach for probability evaluation using Bow-Tie analysis
}

\author{
H. Abdo \& J.-M. Flaus \\ CNRS, G-SCOP, University of Grenoble Alpes, Grenoble, France \\ F. Masse \\ INERIS, Parc Technologique, Verneuil-en-Halatte, France
}

\begin{abstract}
The International Organization for Standardization (ISO) imposes the evaluation of the probability of accidents during risk analysis with the consideration of uncertainty. However, quantitative probability analysis can be too expensive and lead to unreliable estimation. This is due to imprecision and lack of data where unjustifiable assumptions should be added, while quantitative information is lost by using a qualitative probability analysis. This paper proposes a fuzzy semi-quantitative approach to address data uncertainties as an alternative for losing and adding information. A fuzzy-based approach is used for handling vagueness and imprecision in the input parameter frequencies. The application of this approach is demonstrated using the casestudy of a Loss of Containment Scenario (LOC) in a chemical facility.
\end{abstract}

\section{INTRODUCTION}

Probability analysis may be qualitative or quantitative depending on the circumstances (Leitch 2010). Data for performing a probability analysis is either from historical incident data or expert elicitations (Abdo \& Flaus ). Qualitative probability analysis uses a scale of qualitative expressions (low, medium, high, etc.) to describe an event's probability or frequency. The advantage of the qualitative methodology is its simplicity of applying and understanding by the relevant personnel. Expert judgments represent an important source of data to apply this methodology which are subjective (verbal expression) in nature. This subjectivity represents a disadvantage when quantitative or more precise information is available. However, the quantitative approach uses a numerical scale with real values to describe the event frequencies. A disadvantage of the quantitative approach is that the imprecision and lack of such data can affect the quality of the analysis (Abdo \& Flaus 2015). The quantitative methodology is too expensive and complex to be performed in terms of time and cost since statistical and empirical data are needed. It can lead to probability underestimation if uncertainty is not taken into consideration (Abdo \& Flaus 2016). For these disadvantages, a semi-quantitative approach represents a better alternative based on the available information.

INERIS (the French National Institute for Industrial Environment and Risks) has developed an interval semi-quantitative Bow-Tie analysis to quantify the probability of risk based on the available information (De Dianous, Deust, Bouissou, Farret, \& Chaumette 2007). This approach is mainly based onthe INERIS expertise and the results of the European project ARAMIS ((Hourtolou \& Salvi 2003); (Hourtolou \& Salvi 2004)). It uses historical accident data or expert elicitations if the former is not available. It is easy to use, effective and implicitly takes uncertainty into consideration.

This study highlights the limits presented in the interval semi-quantitative approach at first. Then it handles these limits by introducing the concept of fuzzy numbers instead of intervals. Fuzzy numbers are used to represent subjectivity in expert judgments and consider the quantitative data if it exists. The rest of this section provides an introduction to Bow-Tie analysis and the interval semiquantitative approach as a preface to the proposed approach.

\subsection{Bow-Tie analysis}

Bow-Tie analysis is a very prominent method to identify and analyze the probability of risk (Ferdous, Khan, Sadiq. Amyotte, \& Veitch 2012). It presents a combination between Fault Tree Analysis (FTA) and Event Tree Analysis (ETA). FTA and ETA respectively describe the relationship between the undesirable event, its causes and its consequences for a systematic representation of 
hazard ((Sadiq. Saint-Martin. \& Kleiner 2008); (Ferdous, Khan, Sadiq, Amyotte, \& Veitch 2009)). Figure 1 presents a schematic diagram of the BowTie analysis, the definition of each term is detailed in Table 1.

Evaluating probability of an accident using Bow-Tie analysis is performed by: (i) characterizing input data, (ii) propagating these characterizations through the Bow-Tie analysis. Characterizing

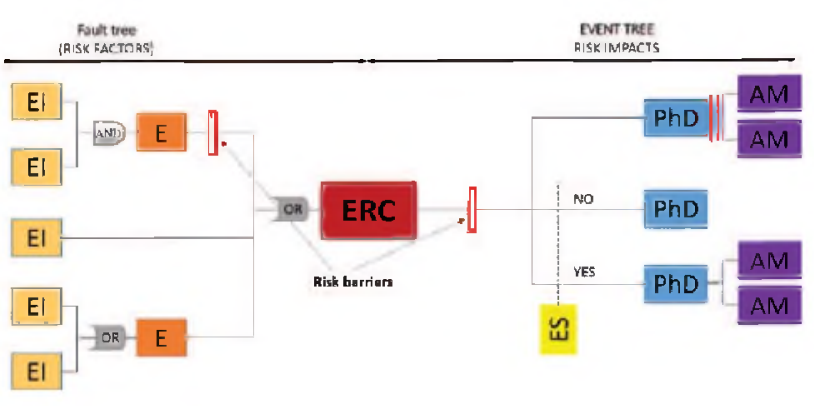

Figure 1. Elements of a "Bow-Tie" diagram.

Table 1. Abbreviations, significations and definitions of elements listed in the Bow-Tie diagram.

\begin{tabular}{|c|c|c|}
\hline Abbreviation & Signification & Definition \\
\hline $\mathrm{EI}$ & Basic event & $\begin{array}{c}\text { Direct cause of a loss } \\
\text { of containment or } \\
\text { physical integrity }\end{array}$ \\
\hline E & Event & $\begin{array}{l}\text { Physical integrity } \\
\text { caused by the } \\
\text { occurrence basic } \\
\text { events }\end{array}$ \\
\hline ERC & $\begin{array}{l}\text { Undesirable } \\
\text { event }\end{array}$ & $\begin{array}{l}\text { The unwanted event } \\
\text { such as a loss of } \\
\text { containment, etc. }\end{array}$ \\
\hline ES & $\begin{array}{l}\text { Secondary } \\
\text { event }\end{array}$ & $\begin{array}{l}\text { Characterize the } \\
\text { source term of an } \\
\text { accident, such as } \\
\text { ignition }\end{array}$ \\
\hline $\mathrm{PhD}$ & $\begin{array}{l}\text { Dangerous } \\
\text { phenomenon }\end{array}$ & $\begin{array}{l}\text { Physical phenomena } \\
\text { that can cause } \\
\text { major accidents, } \\
\text { explosion, } \\
\text { dispersion, fire }\end{array}$ \\
\hline AM & $\begin{array}{l}\text { Major } \\
\text { accident }\end{array}$ & $\begin{array}{l}\text { Damages caused by } \\
\text { the effects of an } \\
\text { PhD on people, } \\
\text { environment or } \\
\text { goods }\end{array}$ \\
\hline | & Risk barrier & $\begin{array}{l}\text { Measures taken place } \\
\text { to reduce the } \\
\text { probability of } \\
\text { undesirable event } \\
\text { and the effects of } \\
\text { accidents }\end{array}$ \\
\hline AND, OR gates & & $\begin{array}{l}\text { Describe the } \\
\text { relationships } \\
\text { between events }\end{array}$ \\
\hline
\end{tabular}

input data aims to qualitatively, quantitatively or semi-quantitatively represent the information provided either by experts or derived from historical data with the consideration of uncertainty. Propagating the characterizations through the Bow-Tie aims to calculate the probability of ERC, PhDs and AMs. This is done by solving the AND and OR gates, considering the existence of risk barriers and the occurrence of secondary events. The next section presents a brief details on the semiquantitative approach used by INERIS to perform a probability analysis.

\subsection{Interval semi-quantitative approach}

Before starting, it should be noted that there is a difference between probability and frequency. But in a simplified manner, these two notions of probability and frequency coincide when frequencies are low (less than 1 time every 10 years). The semi-quantitative scale used by INERIS to characterize the frequency of basic events is presented in Table 2. A class of frequency in terms of an interval is given to each basic event as input. This class is derived from experts, or by translating the quantitative data into a class (e.g. an event with a frequency equals $4 \times 10^{-4}$ is of class F3). This translation is performed based on Equation 1 below:

$$
\operatorname{Class}(f)=-\operatorname{Ent}(\log (f))-1 \text {. }
$$

where, Ent is the integer part, log is the logarithm base 10 and $f$ is the frequency value of the event.

The propagation rules are defined and detailed in (INERIS 2015), and will be presented with additions to suit the fuzzy approach in section 3.4.

The second part of the paper highlights the limitations in the interval semi-quantitative approach. The third part examines the proposed methodologies to deal with the limitations of this approach. Section four presents a case study and compares the fuzzy with the interval semi-quantitative approach and the traditional quantitative approach. Finally, a number of conclusions are drawn in Section 5.

Table 2. Determining the frequency classes based on the semi-quantitative approach.

\begin{tabular}{lcc}
\hline $\mathrm{F}-2$ & $10^{+1} /$ year $\leq$ frequency & 10 to 100 times/year \\
& $\leq 10^{+2} /$ year & \\
$\mathrm{F}-1$ & $10^{\circ} /$ year $\leq$ frequency & 1 to 10 times/year \\
& $\leq 10^{+1} /$ year & \\
$\mathrm{F} 0$ & $10^{-1 / \text { year } \leq \text { frequency }}$ & 1 time every 1 to \\
& $\leq 10^{0} /$ year & 10 years \\
$\mathrm{F} 1$ & $10^{-2} /$ year $\leq$ frequency & 1 time every 10 to \\
& $\leq 10^{-1} /$ year & 100 years \\
$\mathrm{FX}$ & $10^{-(X+1) / \text { year } \leq \text { frequency }}$ & \\
& $\leq 10^{-X} /$ year & \\
\hline
\end{tabular}




\section{PROBLEM STATEMENT}

We shall now introduce the limitations presented in the interval semi-quantitative approach and discuss the methodology behind the proposed solution. These limitations are presented by converting the statistical data into classes:

- The discreteness of the frequency classes makes the conditions on the border between two intervals not well defined. Vagueness on the extent of half the range of the interval to which category it belongs is presented. The same class is given to different frequencies even if the difference between them is too remarkable (see Figure 2(a), the same class $F-1$ is given to events $\mathrm{E} 1$ and $\mathrm{E} 2$ where their frequencies are 11 and 99 per year respectively);

- The interval representation of frequency classes can lead to probability underestimation. Figure 2(b) presents an example of an OR gate of two inputs $E I 1$ and $E I 2$ with quantitative frequencies equal $9.5 \times 10^{-2}$ and $9.6 \times 10^{-2}$ respectively. Suppose that these quantitative information are certain, the quantitative output frequency of the OR gate is equal to $1.05 \times 10^{-1}$. The translation of this quantitative output frequency using the interval scale results in a class $F 0$. While a frequency class equals $F 1$ is obtained based on the interval semi-quantitative approach. The output class of an OR gate based on the interval semi-quantitative approach is presented in Eq. 4;

- If we were wrong in determining the statistical data, i.e. an error factor may affect the statistical value. This error or deviation can lead to a different class and thus to a different result. Figure 2(c) shows an example of an OR gate with two input events EI1 and EI2. The occurrence frequencies of the both input events are equal to 9 times/year. Suppose we have an error factor due to the lack of information or a measurement error, and the frequencies can be higher by a factor of 2 times/year (e.g. 11 times/year). This deviation changes the class of events E1 and E2 from $F-1$ to $F-2$. The output of the OR gate is affected by this error where its class is changed. Thus, a small deviation can lead to a great change in the output.

However, a fuzzy-based approach is proposed in order to address the issues highlighted in this section.

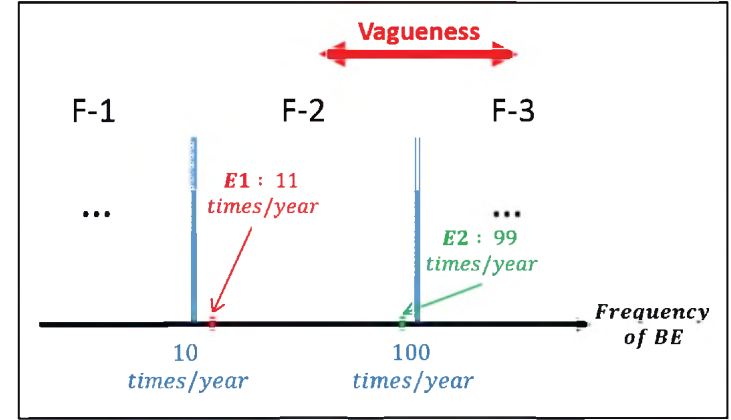

(a) The same class is given to two different values

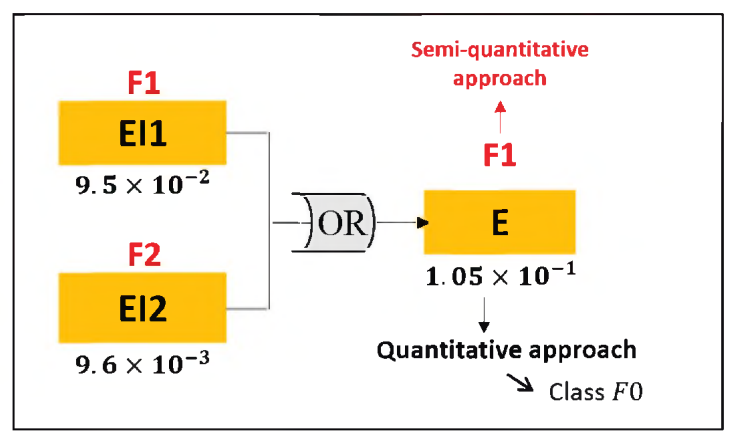

(b) Deviation due to imprecision

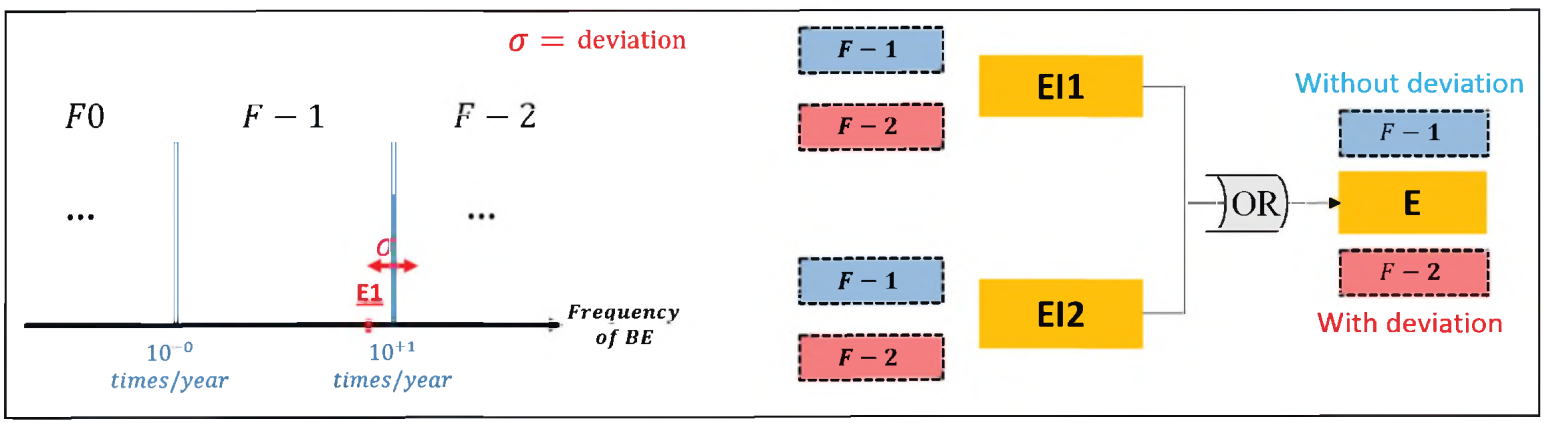

(c) Probability underestimation

Figure 2. Limitations presented in the traditional semi-quantitative approach 


\section{METHODOLOGY}

In this section, we present the added improvements on the INERIS approach. The characterization of input data in terms of fuzzy numbers and the propagation rules to calculate the occurrence probabilities of ERC and outcomes are discussed in the rest of this section.

\subsection{Preliminary}

Fuzzy set was introduced by the pioneer Zadeh in 1965 as a tool to characterize imprecise variables as well as to represent experts' knowledge in a mathematical tool (Zadeh 1965). Fuzzy variable is associated with a possibility distribution or membership function in the same manner as random variable is associated with a probability distribution. Consider a fuzzy subset $F$ of the universal set $X$, thus the membership function is $\mu_{F}: X->[0,1]$. Where, for a given $x \in X$, the membership degree $\mu_{F . X}(x)$ represents the degree of compatibility of the value $x$ with the concept expressed by F. Triangular fuzzy number is the most popular which can be expressed as a triplet $[a, b, c]$, see (Abdo \& Flaus 2016) for more details.

\subsection{Define event frequency using fuzzy mumbers}

Fuzzy numbers are used to express the linguistic frequencies as shown in Figure 3. Since the frequency classes follow a logarithmic scale, the grades $F X, \quad X \in \mathbb{N}$ are not triangular fuzzy numbers. $F X$ is divided in three parts (see Figure 4) and derived with its membership function using Equations 2 and 3 , respectively.

$$
\begin{aligned}
& F X=[a, b, c, d, e]=\left[\frac{10^{-(X+2)}+10^{-(X+1)}}{2} ;\right. \\
& \left.10^{-(X+1)} ; \frac{10^{-(X+1)}+10^{-X}}{2} ; 10^{-X} ; \frac{10^{-X}+10^{-X+1}}{2}\right]
\end{aligned}
$$

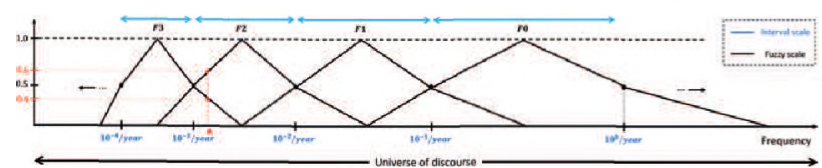

Figure 3. Mapping event frequencies on fuzzy scale.

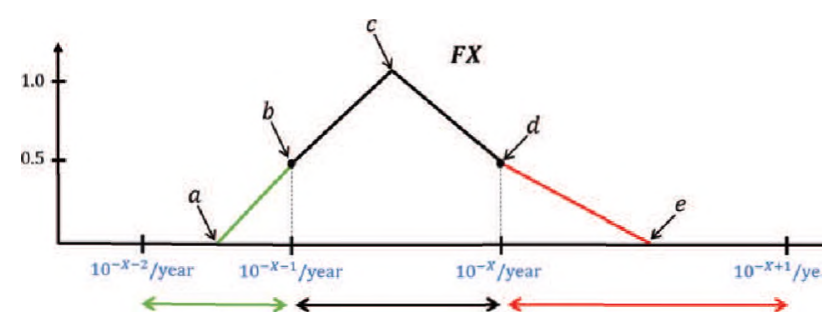

Figure 4. Fuzzy frequency class $F X$.

$$
\mu_{F X}(x)= \begin{cases}\frac{x-a}{b-a} \times 0.5 & a \leq x \leq b \\ 1-\frac{x-c}{b-c} \times 0.5 & b \leq x \leq c \\ 1+\frac{x-c}{c-d} \times 0.5 & c \leq x \leq d \\ \frac{e-x}{e-d} \times 0.5 & d \leq x \leq e\end{cases}
$$

Each value on this scale has its own possibility degrees to which classes it belongs. In the next section, we will define how to represent each type of input data based on the fuzzy semi-quantitative approach.

\subsection{Representation (fuzzification) of input data}

Statistical accident data and expert elicitations are both used in this approach. Thus, precise values and verbal expressions represent the input of the analysis. These inputs are fuzzified and represented as follows:

- The crisp or precise values derived from statistical data are mapped on the universe of discourse. This fuzzification process gives two membership degrees to each crisp value. Figure 3 shows an example of event $\mathrm{A}$ that belongs to classes $\mathrm{F} 3$ and $\mathrm{F} 2$ with membership degrees equal 0.6 and 0.4 respectively. It should be noted that uncertainties attached to statistical values are considered to be covered by the fuzzy classes.

- Experts are asked to give a verbal expression in terms of a frequency class to such an event if statistical data is not provided. This class is taken to be the input for the event.

\subsection{Propagating fuzzy frequencies through the Bow-Tie}

This section aims to set the fuzzy rules for propagating the input frequencies through the Bow-Tie analysis. Propagating inputs is achieved by solving the gates between the events, and aggregating the frequencies of risk barriers and the secondary events. The Fuzzy semi-quantitative rules are presented as follows:

- Treatment of OR and AND gates (section 3.4.1 and 3.4.2 respectively);

- Treatment of secondary events (section 3.4.3);

- Treatment of security barriers (section 3.4.4).

\subsubsection{Treatment of $O R$ gate}

OR gate signifies that the output event occurs if either of the input events has occurred. Figure 5(a) 


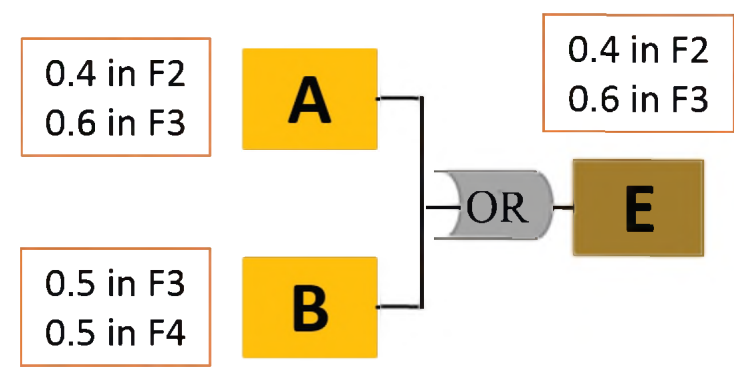

(a) The output of the OR gate based on the fuzzy semi-quantitative approach

\begin{tabular}{|c|c|c|c|}
\hline \multirow{2}{*}{\multicolumn{2}{|c|}{$\begin{array}{l}\text { OR } \\
\text { gate }\end{array}$}} & \multicolumn{2}{|c|}{ Event A } \\
\hline & & F2:0.4 & F3:0.6 \\
\hline \multirow{2}{*}{ 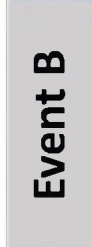 } & 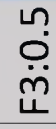 & $F 2: 0.4$ & F3:0.6 \\
\hline & $\begin{array}{l}\text { Un. } \\
\dot{\leftrightarrow} \\
\dot{H}\end{array}$ & $F 2: 0.4$ & $F 3: 0.6$ \\
\hline
\end{tabular}

(b) The output fuzzy frequency of the OR gate obtained by means of the Cartesian product

Figure 5. OR gate example.

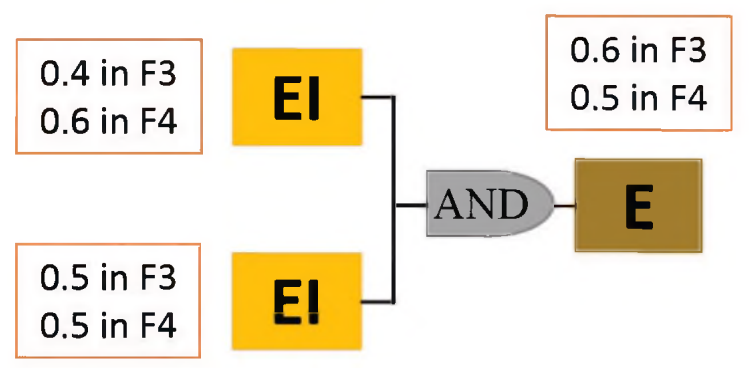

\begin{tabular}{|c|c|c|c|}
\hline \multirow{2}{*}{\multicolumn{2}{|c|}{$\begin{array}{l}\text { AND } \\
\text { gate }\end{array}$}} & \multicolumn{2}{|c|}{ Event A } \\
\hline & & $F 2: 0.4$ & F3:0.6 \\
\hline \multirow{2}{*}{ 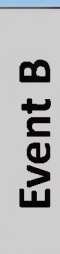 } & $\begin{array}{l}\tilde{0} \\
\ddot{m} \\
\ddot{H}\end{array}$ & F3:0.5 & F3:0.6 \\
\hline & $\begin{array}{l}\text { ஸீ } \\
\dot{+}\end{array}$ & $F 4: 0.5$ & $\mathrm{~F} 4: 0.5$ \\
\hline
\end{tabular}

(a) The output of the AND gate based on the fuzzy semi-quantitative approach

(b) The output fuzzy frequency of the AND gate obtained by means of the Cartesian product

Figure 6. AND gate example.

presents an OR gate with two input events $A$ and $B$. The output event $E$ occurs after the occurrence of $A$ or $B$. Based on the fuzzy approach, each one of $A$ and $B$ may be attached to one or two frequency classes depending on the type of input data (expert or statistical data). The frequency of the OR gate is calculated using the Cartesian product where the Class and the possibility degreeof the table cases are calculated based on the two equations below:

$$
\begin{aligned}
& \operatorname{Class}(E)=\min \left[\operatorname{Class}\left(E I_{1}\right), \operatorname{Class}\left(E I_{2}\right)\right] \\
& \operatorname{Degree}(\operatorname{Class}(E))= \\
& \operatorname{Degree}\left(\min \left[\operatorname{Class}\left(E I_{1}\right), \operatorname{Class}\left(E I_{2}\right)\right]\right)
\end{aligned}
$$

For example, let $\mathrm{A}$ and $\mathrm{B}$ belong to [F3, F2] and $[\mathrm{F} 4, \mathrm{~F} 3]$ with possibility degrees equal $[0.4,0.6]$ and $[0.5,0.5]$ respectively. The Cartesian product for the output is presented in Table 5(b). The output frequency is [F3, F2] with possibility degrees of $[0.5,0.6]$.

\subsubsection{Treatment of AND gate}

AND gate signifies that the output event E occurs if the input events occur simultaneously. The classes and membership degrees of the output event are determined based on Eq. 6 and Eq. 7 respectively. An example is presented in Figure 8(a).

$$
\begin{aligned}
& \operatorname{Class}(E)=\max \left[\operatorname{Class}\left(E I_{1}\right), \operatorname{Class}\left(E I_{2}\right)\right] \\
& \operatorname{Degree}(\operatorname{Class}(E))= \\
& \quad \operatorname{Degree}\left(\max \left[\operatorname{Class}\left(E I_{1}\right), \operatorname{Class}\left(E I_{2}\right)\right]\right)
\end{aligned}
$$

It should be noted that, if the same class $F_{i}$ has different possibility degrees, then the maximum degree between them is selected for the $F_{i}$. As it is the case for class $F 3$ in the example, where 0.6 is taken as the output possibility degree.

\subsubsection{Treatment of secondary events}

PhD1 occurs if ERC occurs and ES occurs conditionally after ERC. PhD2 occurs after the 
occurrence of ERC and no occurrence of ES. The input data here are the frequency classes of the ERC and conditional probability of ES (noted $p$ ). Output frequencies and degrees are calculated using the equations below:

$$
\begin{aligned}
& \operatorname{Class}(\operatorname{PhD} 1)=\max [\operatorname{Class}(\text { ERC })- \\
& \text { Ent }(\log (1-p)-0.5)] ; \text { see }(\operatorname{INERIS} 2015) \\
& \operatorname{Degree}(\operatorname{Class}(P h D 1))=\operatorname{Degree}([\operatorname{Class}(E R C)]) \\
& \operatorname{Class}(\operatorname{PhD} 2)= \\
& \quad \max [\operatorname{Class}(E R C)-\operatorname{Ent}(\log (p)-0.5)] \\
& \operatorname{Degree}(\operatorname{Class}(P h D 2))=\operatorname{Degree}([\operatorname{Class}(E R C)])
\end{aligned}
$$

Figure 7 presents an example.

\subsubsection{Treatment of safety barriers}

A security barrier operates after the occurrence of the event that this barrier is attached to. The output event $\mathrm{E}$ occurs if the input event EI occurs and the attached security barrier does not operate. In the other case (if the security barriers operate), another event $\bar{E}$ may occur.

The data needed for the treatment are the fuzzy frequencies of the event EI and the confidence level of the security barrier. The fuzzy classes of the output events $\mathrm{E}$ and $\bar{E}$ are calculated using the equations below:

$\operatorname{Class}(E)=\operatorname{Class}(E I)+N C=F(x+N C) ;(\operatorname{INERIS~2015)}$

where $\mathrm{x}$ is the class of $\mathrm{EI}$.

$$
\begin{aligned}
& \operatorname{Degree}(\operatorname{Class}(E))=\operatorname{Degree}([\operatorname{Class}(E I)]) \\
& \operatorname{Class}(\bar{E})=\operatorname{Class}(E I) \\
& \operatorname{Degree}(\operatorname{Class}(\bar{E}))=\operatorname{Degree}([\operatorname{Class}(E I)])
\end{aligned}
$$

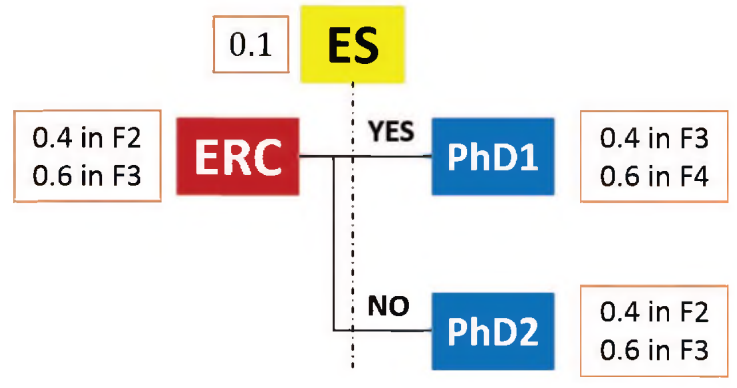

(a) The fuzzy output of dangerous phenomena after the occurrence of an ES

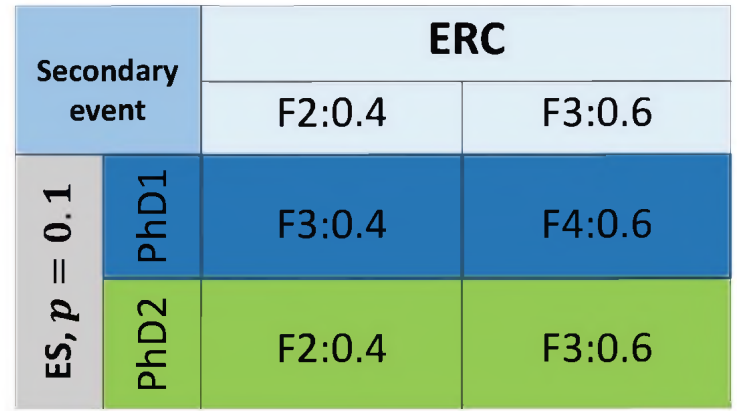

(b) The output fuzzy frequency of $\mathrm{PhD} 1$ and $\mathrm{PhD} 2$ obtained by means of the Cartesian product

Figure 7. Consideration of a ES within the fuzzy semi quantitative approach.

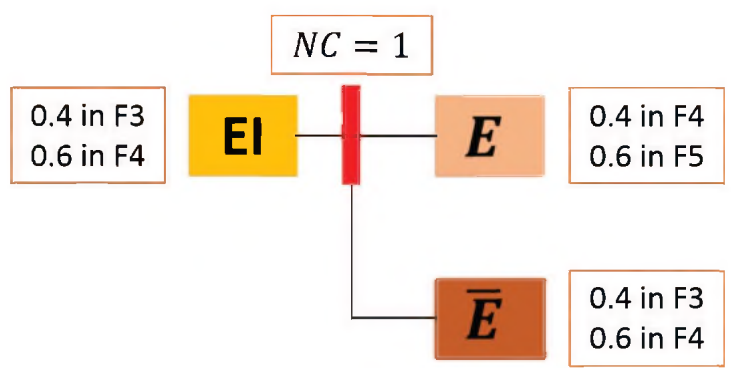

(a) The fuzzy outputs of events $E$ and $\bar{E}$

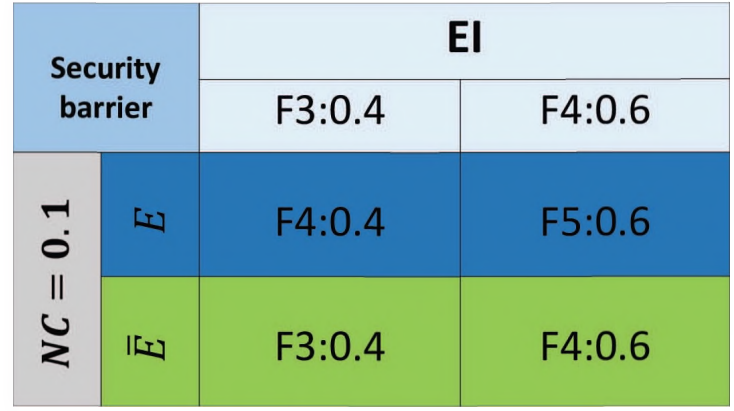

(b) The output fuzzy frequency of $E$ and $\bar{E}$ obtained by means of the Cartesian product

Figure 8. Consideration of a security barrier within the fuzzy semi quantitative approach. 


\section{HOW THE FUZZY APPROACH HANDLES THE EXISTED LIMITS}

However, Figure 9 presents how the proposed methodology deals with the limitations presented in the interval semi-quantitative approach. For the discreteness issue. now the events E1 and E2 are now belong to different classes with different degrees (see Figure 9(a)). Figure 9(b) presents how the fuzzy approach solves the probability underestimation problem. Finally, A deviation due to error in the determination of input frequencies will not affect the result nor the decision. The same example taken in Section 2 is depicted in Figure 10. A small change in the possibility degrees is generated due to the deviation where the classes are the same. Here the effectiveness of fuzzy theory in handling uncertainty lies in.

This methodology will be illustrated in the next section and applied to a loss of containment scenario.

\section{ILLUSTRATION OF THE PROPOSED APPROACH}

In this section, a Bow-Tie analysis for a LOC scenario is utilized to prove the utility and effectiveness of the proposed methodology, shown in Figure 11. The proposed methodology is applied

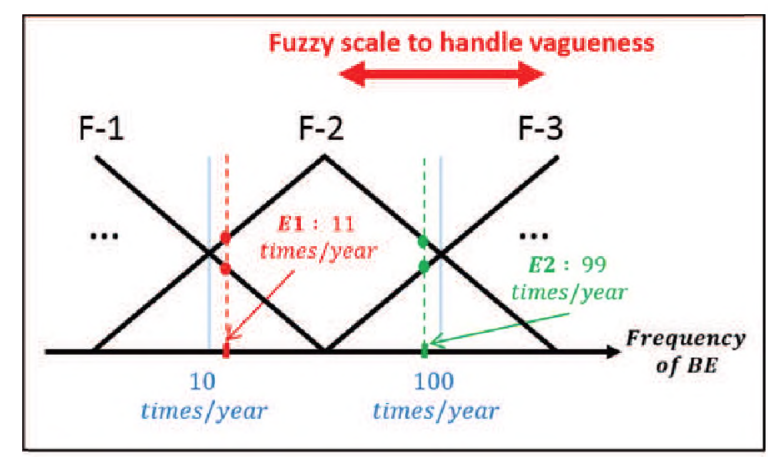

(a) Handling vagueness

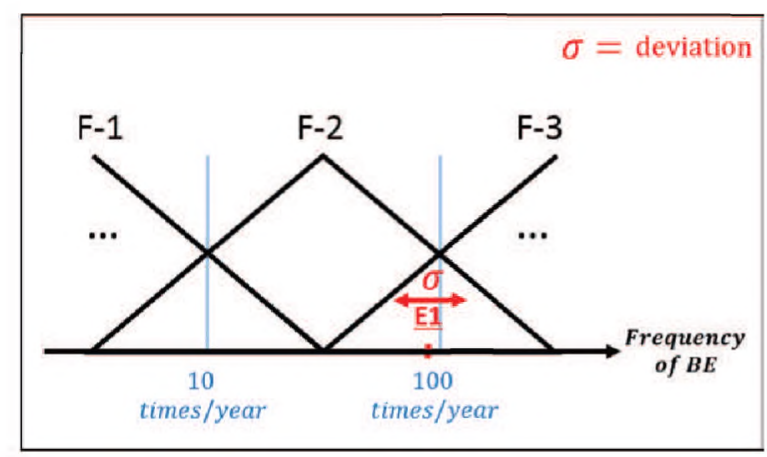

(b) Conservative estimation of output probabilities

Figure 9. How the fuzzy semi-quantitative approach deals with the limitations mentioned in Section 2.
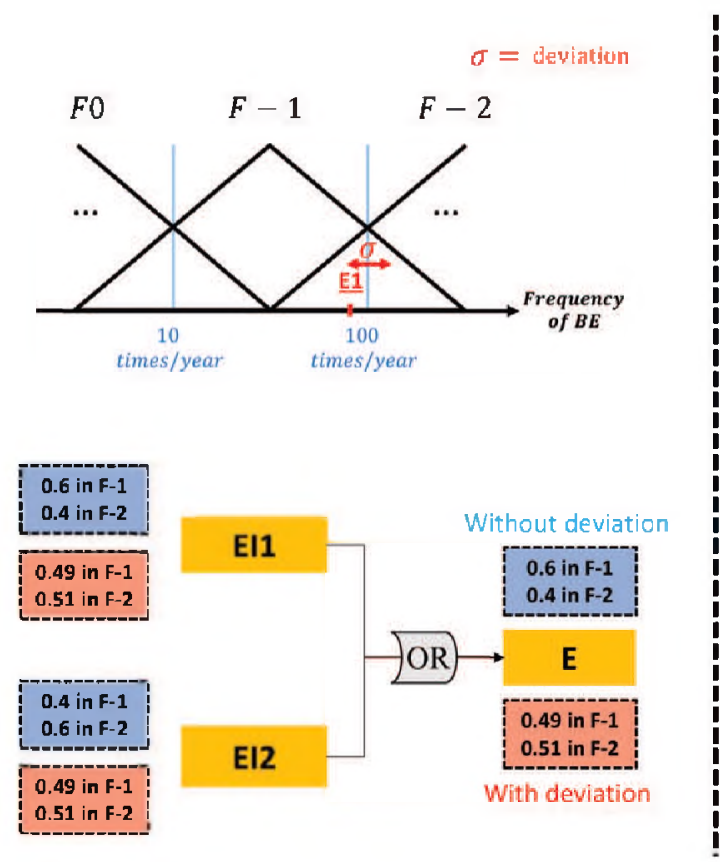

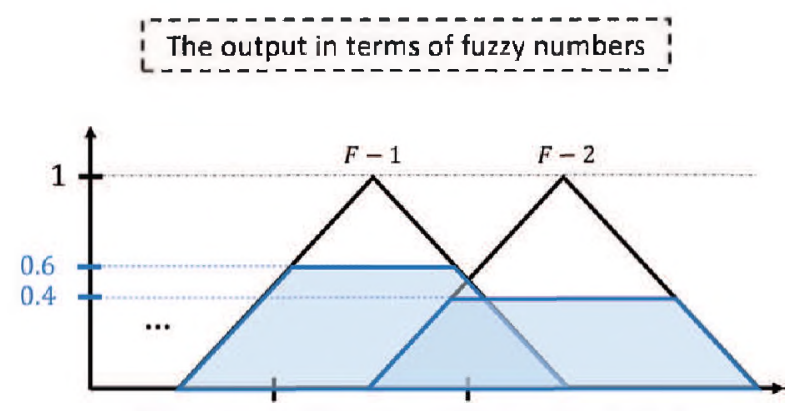

The output without considering the deviation

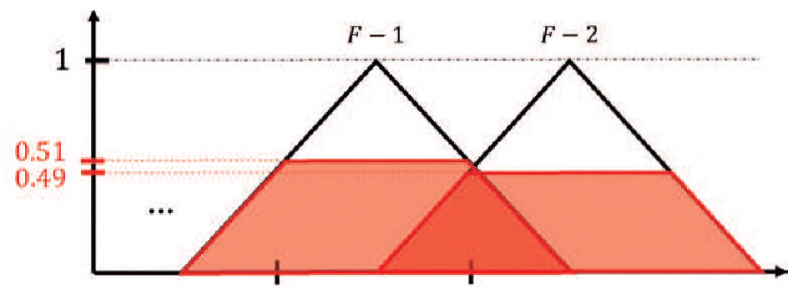

The output with considering the deviation

Figure 10. A deviation will not lead to different result that affects the decision. 


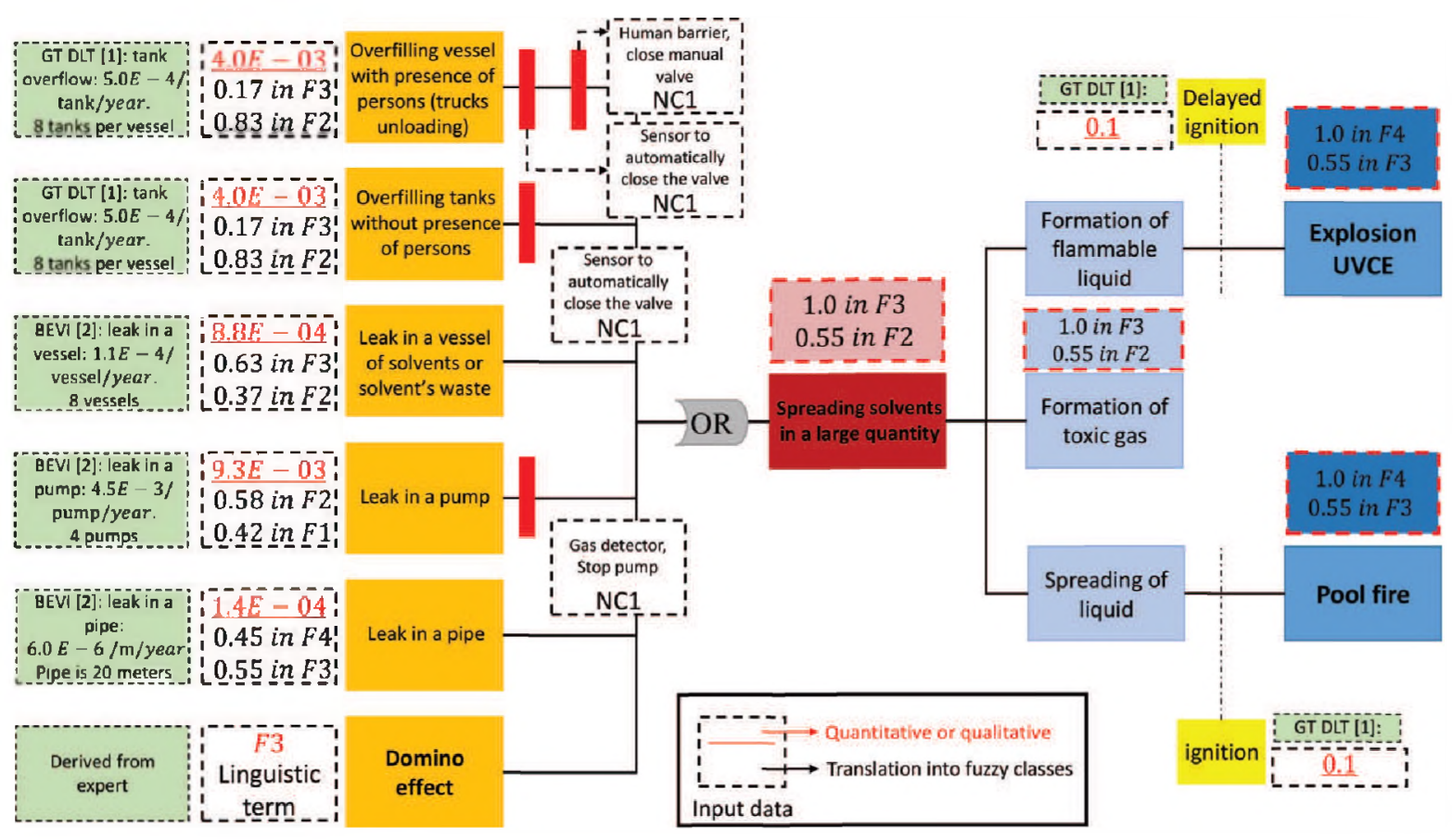

Figure 11. The Bow-Tie diagram of the LOC scenario under study.

to the Bow-Tie to determine the frequencies of dangerous phenomena. The input frequencies were collected from two different data bases ((for Industrial Environment \& (INERIS) 2008); (Center for External Safety \& the Environment 2009)) and an expert in the field. These frequencies are translated into fuzzy classes (the dashed rectangle beside each event or risk barrier). These fuzzy classes are propagated through the Bow-Tie using the fuzzy rules set in Section 3.4. The output fuzzy frequencies of the ERC and outcomes are written on the Bow-Tie (the red dashed rectangles in Figure 11).

In addition to the proposed approach, quantitative and interval semi-quantitative analyses were also performed for the Bow-Tie of LOC scenario. In order to compare these approaches, the outputs are presented in Table 3. The output frequencies of the quantitative approach are translated into classes for comparison purposes. The quantitative approach is the most precise but it does not consider uncertainty in the analysis. As there is no consideration of uncertainty, this may lead to risk underestimation in some cases. However, the fuzzy approach presents more accuracy than the interval approach where the output fuzzy classes cover the class obtained using the quantitative approach. Fuzzy approach is more conservative than the quantitative approach as uncertainty is considered (fuzzy numbers are used instead of crisp values). Again the exact result from the quantitative approach lies within the result obtained by the proposed approach, which makes the later more conservative.
Table 3. Estimated results obtained using quantitative, interval semi-quantitative and fuzzy semi quantitative approaches.

\begin{tabular}{|c|c|c|c|}
\hline Outcomes & $\begin{array}{l}\text { Quantitative } \\
\text { approach }\end{array}$ & $\begin{array}{l}\text { Interval semi- } \\
\text { quantitative } \\
\text { approach }\end{array}$ & $\begin{array}{l}\text { Fuzzy semi } \\
\text { quantitative } \\
\text { approach }\end{array}$ \\
\hline $\begin{array}{l}\text { Spreading } \\
\text { solvents } \\
\text { in a large } \\
\text { quantity }\end{array}$ & $2.1 \times 10^{-5}: \underline{F 2}$ & F3 & $\begin{array}{l}1.0 \text { in } \mathrm{F} 3 \\
0.55 \text { in } \mathrm{F} 2\end{array}$ \\
\hline $\begin{array}{l}\text { Explosion } \\
\text { UVCE }\end{array}$ & $2.1 \times 10^{-4}: \underline{\mathrm{F} 3}$ & F4 & $\begin{array}{l}1.0 \text { in } \mathrm{F} 4 \\
0.55 \text { in } \mathrm{F} 3\end{array}$ \\
\hline $\begin{array}{l}\text { Formation } \\
\text { of toxic } \\
\text { gas }\end{array}$ & $2.1 \times 10^{-3}: \underline{F 2}$ & F3 & $\begin{array}{l}1.0 \text { in F3 } \\
0.55 \text { in F2 }\end{array}$ \\
\hline Pool fire & $2.1 \times 10^{-4}: \underline{\mathrm{F} 3}$ & $\mathrm{~F} 4$ & $\begin{array}{l}1.0 \text { in } F 4 \\
0.55 \text { in } F 3\end{array}$ \\
\hline
\end{tabular}

\section{CONCLUSION}

Probability analysis of dangerous phenomena has become a necessary step in risk analysis. Qualitative or quantitative probability analysis can be performed depending on the type of data available. This data is derived from different sources (historical accident data or expert judgments in terms of numerical values or linguistic variables, respectively). Quantitative information for a quantitative analysis is not always provided. Qualitative analysis is subjective and may lead to loss of quantitative information if it exists. In addition, the accuracy of the analysis based on these approaches still a 
major issue since uncertainty is not taken into consideration.

That is why this paper proposes a fuzzy-semi quantitative approach relying on the available information from historical data or experts if the former is not available. Fuzzy theory is introduced to handle uncertainty due to imprecision and vagueness in defining the frequency scale. Fuzzy rules are set to propagate the fuzzy input classes through the Bow-Tie analysis. BT analysis is used to model a risk scenario as it gives an exhaustive visual summary of risk by displaying the risk events and the control measures and as a tool for likelihood evaluation.

This methodology is applied to a Bow-Tie case study for a LOC scenario. A comparison with the quantitative and the interval semi-quantitative approaches is discussed. The results show that the proposed methodology provides more simplicity and accuracy in the quantification, in addition to the consideration of uncertainty.

In the future, this work will be extended by using multiple sources of data in probability analysis. Different data bases or experts may provide different probabilities regarding the same parameter. Thus, rating and aggregating the data from different sources will lead to a more robust probability quantification approach for Bow-Tie analysis.

\section{ACKNOWLEDGMENTS}

This work is based on research supported and funded by the French National Institute for Industrial Environment and Risks (INERIS).

\section{REFERENCES}

Abdo, H. \& J. Flaus (2015). A mixed fuzzy probabilistic approach for risk assessment of dynamic systems. IFACPapers OnLine 48(3), 960-965.

Abdo, H. \& J.-M. Flaus. Uncertainty quantification in bow-tie analysis: A mixed approach of fuzzy theory with dempstershafer theory of evidence. In Risk, Reliability and Safety: Innovating Theory and Practice: Proceedings of ESREL 2016. Taylor \& Francis.

Abdo, H. \& J.-M. Flaus (2016). Uncertainty quantification in dynamic system risk assessment: a new approach with randomness and fuzzy theory. International Journal of Production Research, 1-24.

Center for External Safety, N.N.I. o. P.H. \& the Environment (2009). Reference manual BEVI risk assessments, Volume v3.1.

De Dianous, V., C. Deust, C. Bouissou, R. Farret, \& S. Chaumette (2007). Prise en compte de la probabilité dans les études de dangers. Préventique Sécurité (95), 32-37.

Ferdous, R., F. Khan, R. Sadiq, P. Amyotte, \& B. Veitch (2009). Handling data uncertainties in event tree analysis. Process safety and environmental protection 87(5), $283-292$.

Ferdous, R., F. Khan, R. Sadiq, P. Amyotte, \& B. Veitch (2012). Handling and updating uncertain information in bow-tie analysis. Journal of Loss Prevention in the Process Industries 25(1), 8-19.

for Industrial Environment, F.N.I. \& R. (INERIS) (2008). Guidede maitrise des risques technologiques dans les depots de liquides inflammables, Volume 8. 10.

Hourtolou, D. \& O. Salvi (2003). Aramis project: development of an integrated accidental risk assessment methology for industries in the framework of seveso ii directive. In International Conference on Safety and Reliability (ESREL 2003), pp. 829-836.

Hourtolou, D. \& O. Salvi (2004). Aramis project: Achievement of the integrated methodology and discussion about its usability from the case studies carried out on real test seveso ii sites. In 11. International Symposium on Loss Prevention and Safety Promotion in the Process Industry, pp. 1133-1143. PetroChemEng. Praha.

INERIS (2015). Agrégation semi-quantitative des probabilits dans les études de dangers des installations classées - Omega Probabilités.

Leitch, M. (2010). Iso 31000: 2009 the new international standard on risk management. Risk Analysis 30(6), $887-892$.

Sadiq, R., E. Saint-Martin, \& Y. Kleiner (2008). Predicting risk of water quality failures in distribution networks under uncertainties using fault-tree analysis. Urban Water Journal 5(4), 287-304.

Zadeh, L. (1965). Fuzzy sets. Information and Control $8(3), 338-353$ 